\title{
The Mature Imagination and Consumption Strategies
}

\section{Age and Generation in the Development of a United Kingdom Baby Boomer Identity}

\author{
BY SimON BIGGS ${ }^{1}$, CHRIS PHILLIPSON ${ }^{2}$, REBECCA LEACH ${ }^{3}$ AND \\ ANNE-MARIE MONEY4
}

\begin{abstract}
Baby boomers have been credited with an essentially 'youthful' approach to themselves, to consumption and to life-style. As they enter midlife and older age they are also faced with the challenges of a mature identity. This paper critically examines the strategies that baby boomers in the United Kingdom use to manage identity as they grow older. Specifically, questions concerning attitudes to cohort labels, personal ageing and other generations are compared to the consumption choices that are made in areas considered to be key to an ageing identity, including: appearance, clothing and bodily maintenance. Boomers identify with succeeding rather than preceding generations. While they claim not to be concerned with bodily ageing as such, their strategies are aimed at maintaining a

1 Simon Biggs, Institute of Gerontology, King's College, London, UK.

2 Chris Phillipson, Centre for Social Gerontology, Keele University, UK.

3 Rebecca Leach, School of Criminology, Education \& Social Work, Keele University, UK.

4 Anne-Marie Money, Centre for Occupational and Environmental Health, The University of Manchester, UK.
\end{abstract}


balance between youthful and mature identities. Priority was given to blurring the boundaries between themselves and younger adult generations. The implications for the relationship between adult ageing and patterns of consumption are explored.

Keywords: Baby boomer, sixties generation, mature identity, youthful identity, consumption, mid-life, appearance, fitness and exercise

\section{Introduction}

Baby boomers (defined as those born in the late 1940s and early 1950s) have become a focus of interest for at least two reasons. First, they have been credited as the harbingers of a characteristically 'youthful' approach to culture and as being the $20^{\text {th }}$ century's 'first teenagers' (Huber \& Skidmore 2003). They were children in a period of post-war austerity, but with adulthood coinciding with the rise of consumer society (Kynaston 2007; Sandbrook 2005) and carried with them hopes for a new and better society. It has been argued that, as a consequence, boomers grew up at a time of cultural shift, with traditional values being questioned and new opportunities for self-expression becoming available. Edmunds and Turner (2002) suggest, for example, that boomers were a 'strategic generation in aesthetic, cultural and sexual terms'. As such, the baby boomer cohort came of age, developed an adult identity and lifestyle habits, in circumstances that Mannheim (1952) has described as most likely to provoke a sense of a self-conscious generational identity among its members. They experienced, at a period of adult identity formation, historical and social shifts that had the potential to turn a cohort of people who happen to be born at the same time into a group with a particular sense of collective awareness that is then carried with them as they travel through the life course. The boomer cohort thereby achieved an iconic cultural status as a radical, liberal and above all 'youthful' generation. Whether or not this is true in practice, it has become an assumption on which contemporary boomers may have to take a stand, a viewpoint that affects their sense of who they are.

Second, baby boomers have become a focus of interest at the beginning of the $21^{\text {st }}$ century because such a large cohort has not survived into 
later life in contemporary memory, and may be historically unprecedented. Spending the adult years in a period marked by rapid change in social attitudes toward gender roles, race and sexual orientation, has raised the question of whether boomers will also provoke changes in the social construction of later life. The majority of this cohort is presented as both fitter and richer (Metz \& Underwood 2005) than preceding ones, giving them the opportunity to use an expanded consumer culture to build lifestyles and identities that challenge traditional attitudes toward adult ageing. Gilleard \& Higgs (2002) view them as a mid-century generation that 'broke the mould of the modern life course' coinciding with a wider cultural drift away from self definition in terms of production (what one does at work) to the perceived freedoms of consumer activity (how one creates a personal lifestyle). Individual members of such a large cohort are driven, according to Stewart and Torges (2006), to social and psychological expressions of individuality: desires feed back into the economy to provide greater consumer choice around adult ageing. Consumption supplies a multiplicity of props that can be used to create desired identities, and the question arises whether boomers will take advantage of these opportunities to re-define what it means to grow old. Specifically, what strategies might they use to balance the management of a mature identity, while maintaining an essentially youthful outlook on life?

\section{Research Questions for a Mature Identity}

The interaction between adult ageing, cohort labels and consumption is the focus of the rest of this paper. It will draw on research undertaken for the Economic and Social Research Council/Arts and Humanities Research Council's Cultures of Consumption Programme, with the project title 'Boomers and Beyond: intergenerational consumption and the mature imagination'. Here, four areas were identified that linked questions of consumption, age-identity and the baby boomer cohort: their attitudes to personal ageing, attitudes to younger and older generational groups, whether or not respondents identified with 'boomer' as a cohort label, and the strategies adopted to maintain an ageing identity. 
First, a youthful self has been identified with theories linking consumption and identity (Featherstone \& Hepworth 1989) and a mature self with a life course-based approach to ageing (Biggs 1999). The former position suggests growing uniformity between older and younger age groups, whereas the latter proposes a growing distinctiveness of identity with age and an increased focus on existential issues associated with growing older (Biggs 2005). One aim of the research was thus to explore these two models and their consequences for patterns of consumption in later life.

Secondly, baby boomers have been associated with a disidentification with previous generations and identification with younger generations (Harkin \& Huber 2004; Gilleard \& Higgs 2005). This conception of identity draws on the early work of Mannheim (1952), arguing that a generationally self-aware cohort would experience certain formative youthful events that create a rift between themselves and preceding generations. These positions suggest that identity is focused on youthful experience and a rejection of the old.

Thirdly, a number of writers (Woodward 1991; Biggs 1999; Grenier 2007) have argued that rather than passively responding to age expectations, adults engage in active strategies that serve to position themselves in relation to inter-generational encounters. It is quite possible that baby boomers use consumption as part of their wider strategies in coping with the challenge of growing older. Discovering the ways that boomers deploy consumption practices in the service of an ageing identity was a final research objective.

The demographic patterning of UK baby boomers consists of two waves, which peak in 1947 and 1964, respectively. For the purposes of the ESRC/AHRC project, research was based upon so-called 'first wave' baby boomers, defined as those born between 1945 and 1954. The core of the research comprised primary data collection with 150 baby boomers together with 30 follow-up, in-depth, biographical interviews. The sample consists of people born between 1945 and 1954, living in South Manchester, England. The characteristics of the sample did not differ significantly from the same age group in the wider UK population. Analysis of these interviews has provided unique insights into consumption patterns and lifestyles among the boomer generation. In each case trends in the 
quantitative data from the first phase of interviews were expanded through qualitative responses and the in depth follow-up interviews. In view of the small sample size, quantitative data is largely descriptive and is interpreted by using the richer, qualitative material. Qualitative citations have been selected to reflect typical patterns of responding.

\section{Operationalising Youthful and Mature Selves}

It is clear from the introduction that baby boomers constitute a cultural as well as a demographic phenomenon. In order to investigate the relationship between changing attitudes to ageing and patterns of consumption, the previously conceptual distinction between the youthful and mature self required an operational definition. The project could then generate empirical evidence on the basis of which either of those identity positions could be identified or a new formulation could emerge. An operational definition emerged from a close reading of the theoretical base and isolating components of the two positions. Questions were then created for the first series of interviews and in subsequent in-depth interviews that either reflected these components directly or allowed certain identity positions to be inferred:

- The 'Youthful Self' position would be inferred from a looking back to youth and childhood, references to and continuities with one's own youth, identification with the younger generation and feeling young inside.

- The 'Mature Self' was made operational through looking forward to the time one had left in life course terms, a focus on current issues, identification with a peer generation and feelings of satisfaction with actual chronological age. These components were then turned into open-ended questions that were used to generate qualitative narrative material.

Material was collected through a number of methods. First, a series of discrete questions was asked as part of a semi-structured interview questionnaire, administered face-to-face, including the 'age discrepancy' items described below. Secondly, an in depth interview was subse- 
quently undertaken, using probe questions aimed at generating freeflowing narrative content around topics identified by the original research questions (consumption practices, personal, social and societal attitudes to ageing, attitudes to other generational groups). The material was analysed in two ways, according to thematic content that had been coded as addressing the research questions, and, by the use of a modified grounded theory approach that allowed themes to emerge from the data without reference to the core themes. Codes were generated by two researchers working independently from each other; they were then cross checked by each member of the research team. Agreement by three researchers was needed before data was given a final thematic location.

An 'age discrepancy' score was also developed from the work of Kaufman and Elder (2002) to create a numerical score for different forms of age as experienced. This consisted of taking scores given on three dimensions: the age respondents felt inside (subjective), thought others saw them (social) and would like to be (ideal), from their chronological age. A positive score indicated that the respondent felt 'younger' and a negative score 'older' on each dimension. Pilot interviews $(n=4)$ indicated that respondents did not experience difficulty in performing this task; it allowed numerical access to specific experiences of adult ageing that could then be compared to other scores.

\section{Ageing \& Generation}

\section{Attitudes to Personal and Social Ageing}

A series of direct questions was asked about how important respondents thought age was to their personal and social identities. It appeared that far fewer boomers thought age was important to their sense of who they were $30 \%(n=45)$ than felt that this was not very important $70 \%(n=105)$. Similarly, only $37 \%(n=55)$ reported that other people's perception of their age was important to them; $62 \%(n=93)$ claiming that this was not important. This finding was supported by qualitative interview data where respondents reported to be less concerned with age as a marker of identity than they had been when they were younger: 
I've spent my whole life up to 25 wanting to be older, because I saw those people in the positions that I wanted to be... but then when I reached it I was no better off, so it was a total waste of time. (Male: 52 yrs)

A typical response can be found from this fifty three year old woman: “Certain things become less important. It doesn't really matter quite as much what people think about you".

As such these results reflect a mature identity in so far as a reduced dependence on the opinion of others and salience of age as a factor in support of one's identity, suggest a coming to terms with current agecircumstances. Awareness of personal ageing was most often associated with peripheral physical signs - such as wrinkles - rather than serious physical disability, which was seen to mark the advent of old age itself. A common response was that this was an age marked by relative financial security, good health and being at ease with oneself, for example:

Well, at the moment we have no money worries... Like I'm in a settled relationship, there's no big traumas in my life. I'm more at ease with myself and I don't bother what people think about me as much as I used to when I was younger... I've got more freedom now. (Female: $55 \mathrm{yrs}$ )

Age discrepancy scores for the baby boomer cohort indicated some interesting trends in the way that boomers thought about their identity and its relation to adult ageing (although not all of the possible 150 respondents answered the discrepancy questions, with drop outs averaging at $4 \%$ ). In terms of subjective age, it appeared that almost all respondents (barring $2 \%, n=3$ ) felt younger inside than their actual age, supporting the "youthful' position (see Figure One). This would appear to be a larger percentage than that identified in a study of people 60 and over (Bernard et al. 2004).

The trend toward feeling youthful inside is also reflected in respondents' self reports across the boomer age-span:

When I look in the mirror I don't see myself, if you understand what I mean. I feel... I don't feel my age. (Female: 58 yrs) 
Figure 1. Age Discrepancy Scores for Subjective Age: Actual Age minus Age 'Feel inside'.

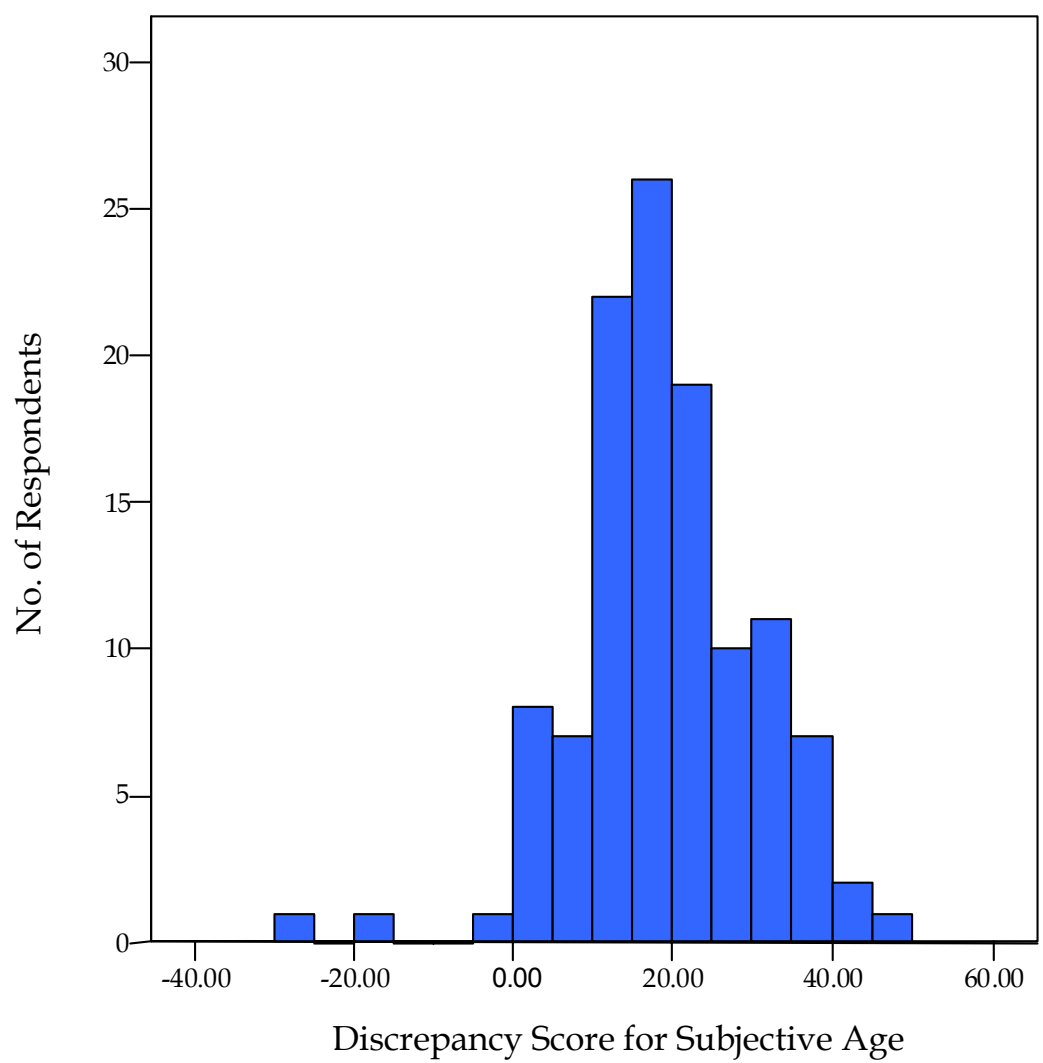

I think part of the problem is that I don't feel 51. Sometimes I see people and I think "God, they're younger than me". (Female: 51 yrs)

Attitudes toward ageing? I kind of still think we won't grow old attitude. Fifty isn't old. People are now saying sixty isn't old and I have friends who are in their sixties. But I don't consider sixty is old these days. (Male: $57 \mathrm{yrs}$ ). 
Figure 2. Age Discrepancy Scores for Social Age: Actual Age minus 'How others see me'.

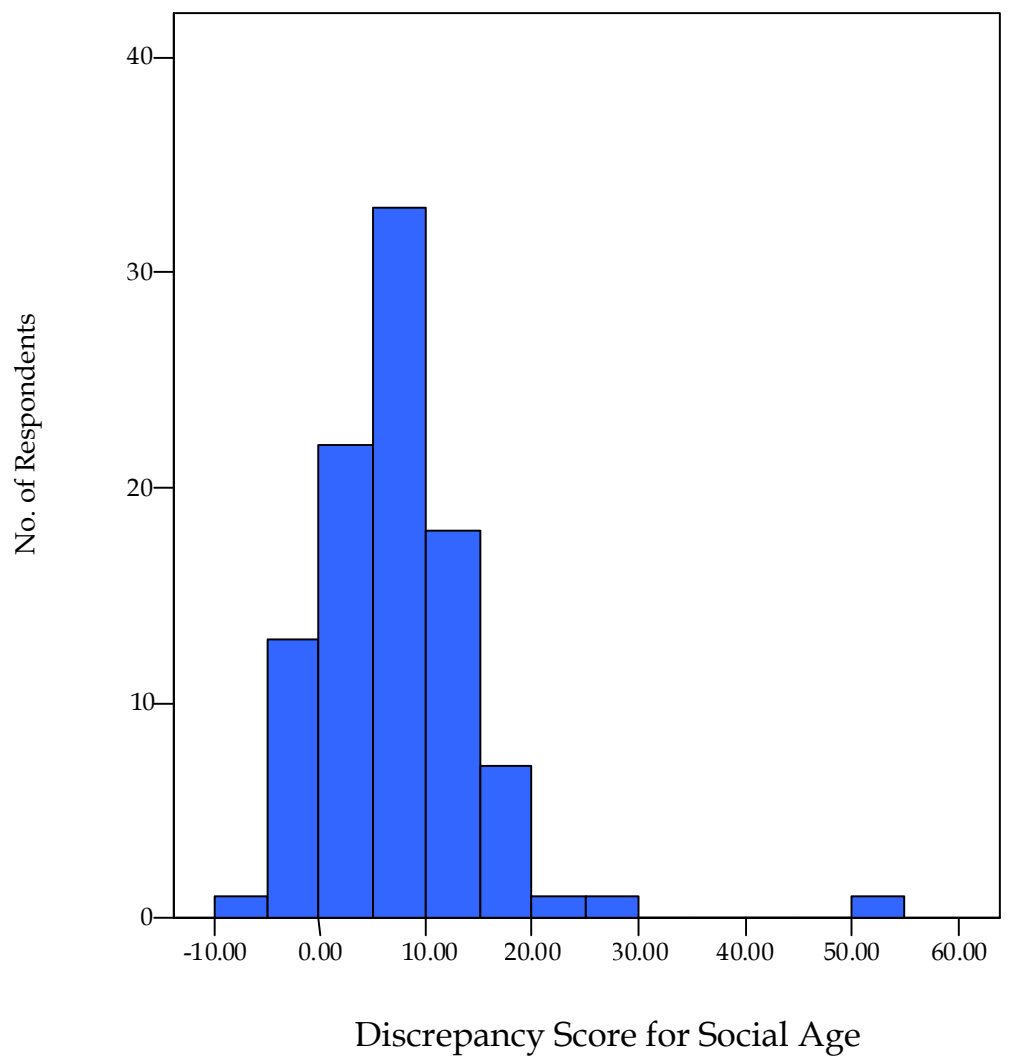

The modal age discrepancy score was plus 20, meaning that the most commonly cited difference between actual and felt ages was a difference of twenty years. This gives some validity to the popular dictum that " 60 is the new $40^{\prime}$, which may really be the case, at least in terms of what many baby boomers consider their subjective age to be. 
Social age discrepancies, or the age respondents thought they appeared to others, peaked at 10 years younger than actual age, with all individuals who responded to this question, seeing themselves as looking younger than their actual age $(n=144)$ (see figure 2).

This again supports the 'youthful' position. Boomers thought that they appeared younger than they considered people of their age should generally look:

Some people have expressed surprise and they've known that I've been, you know 53. I think there's some people that perhaps think I'm maybe 45 or something. (Female: 53 yrs.)

'I don't know whether its flattery, most people see me as a bit younger than fifty-eight. So, um, turning fifty probably' (Female: 58 yrs).

Interviewer:

And how important is age a factor in how other people think about you?

Respondent:

I don't think it is very important actually. (Female: $59 \mathrm{yrs}$ ).

However, the ideal age that boomers would like to be indicated a modal majority at actual, chronological age $(38 \% n=43)$, with a small aspirational hump peaking at twenty years younger (see figure three). This supports the view that Boomers experience a general satisfaction and coming to terms with the age they are, plus a sense that they are less concerned by age than they had been during earlier phases of the life course.

This perception is reflected in the qualitative data and supports the 'mature identity' position:

No I actually like the age I am, I am actually really enjoying my life at the moment. I get a very big challenging day at work and when I come here and it's an oasis of calm. I'm not driven by my hormones. (Female: 60 yrs)

No need to be older or younger. (Male: $55 \mathrm{yrs)}$ 
Figure 3. Age Discrepancy Scores for Ideal Age: Actual Age minus 'Would like to be'.

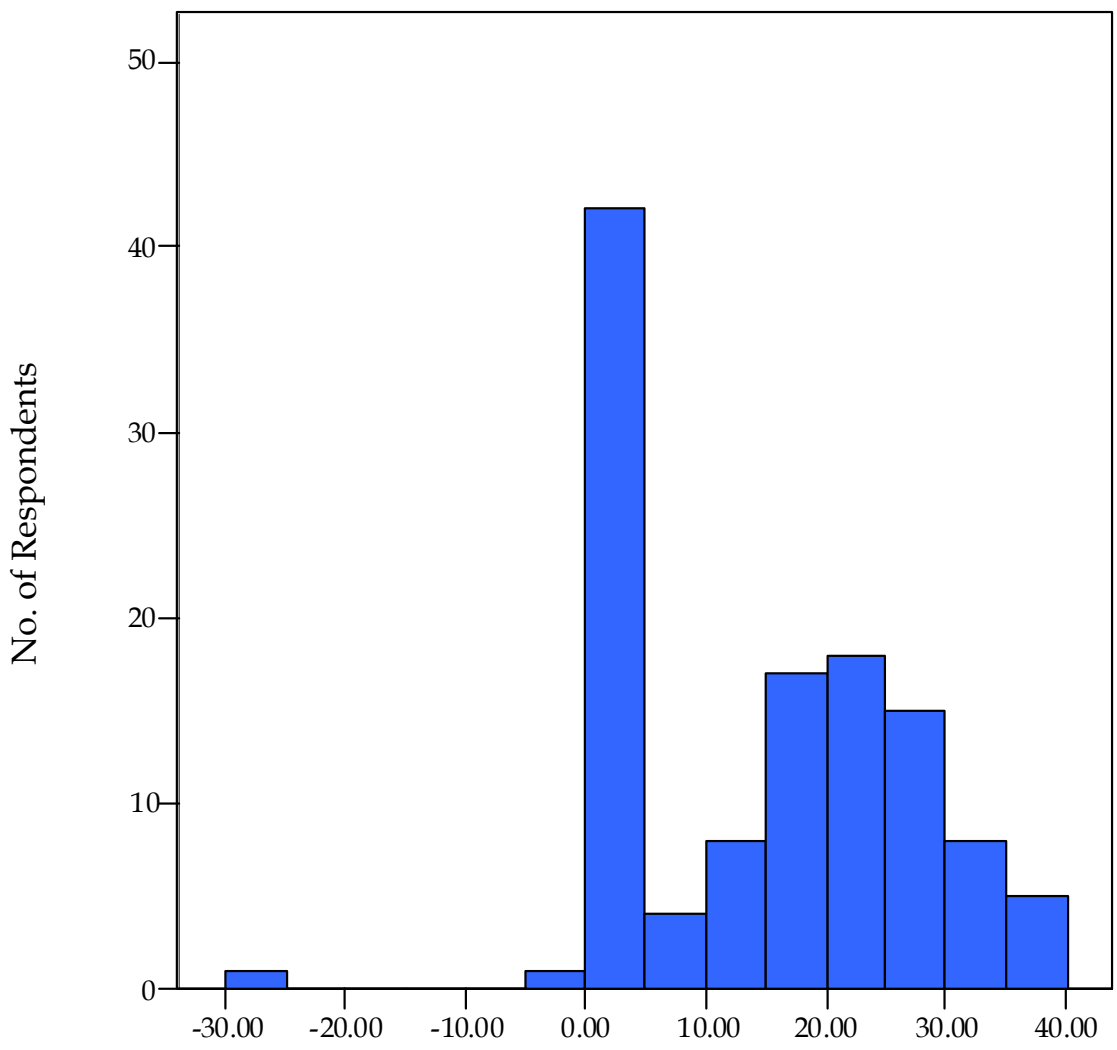

Discrepancy Score for Ideal Age

I don't see myself as old, but neither do I see myself in a way as being young or in my, as if I was still in my early thirties. Because I think I've learned a lot since then. (Female: $55 \mathrm{yrs}$ )

Difficult really. I don't want to grow old but I want to be... you know, I am what I am. (Male: $59 \mathrm{yrs}$ ) 
The majority of our cohort considered themselves to be comfortable with the age they found themselves to be, for example:

Um, I think you feel comfortable in yourself. I feel more confident, I think, probably, because you know what your capabilities are. (Female: 58 yrs).

The advantages of being my age are... Experience and not having to think about how other people think of you. (Male: $57 \mathrm{yrs}$ )

Respondent:

I don't like the limited life, the amount of time I might have left, but.

Interviewer:

But you're quite happy being 58 ?

Respondent:

I'm quite happy being it, yes, yes, very relaxed about it. (Female: 58 yrs)

While $42 \%(n=56)$ of respondents reported that they thought of their lives in terms of time since childhood or youth, $51 \%(n=69)$ indicated that they thought of it in terms of the time they had left. This indicates a relatively even split between those who calibrated their life course by looking back and those who looked forward and were primarily thinking about the future. As such it shows a mixture of youthful and mature identity markers:

When you get to a certain age you want to start mapping your life out but you don't want to give anything up do you? (Male: 58 yrs)

I don't look back but I look forward to the time I've got left.... For me it's very much with what I've got left to do with the time I've got left. (Female: $57 \mathrm{yrs}$ )

It is tempting to speculate that boomers have a sense, sometimes articulated in the qualitative data, of what someone their age would otherwise be like, a socially constructed idea of what a person in their mid- to latefifties should be, to which they are an exception: 
If you thought the idea of middle age being a period when you became - started to become slightly staid and boring - I would say, hopefully I haven't got there yet, but on the other hand if you sort of said, is middle age a phase of life as opposed to an attitude... because you had the idea at one time if you were a middle-aged man in a sort of tweed jacket and pipe and walking dogs. (Male: 53 yrs)

I was sixty last month and when my dad was sixty and my mum was sixty they were old people, and I really only think of myself as forty. They were thinking of coming to the end of their life but I've got no intention [of thinking in this way]. (Male: $60 \mathrm{yrs}$ )

Attitudes to personal ageing can, however, shade into a state of denial about the ageing process itself:

I kind of think we won't grow old, fifty isn't old. (Male: 57 yrs)

You're as young as you feel. I don't think it's very important to be honest with you. (Female: 61 yrs)

It's all psychological I think. It's all in the mind. (Male: 55 yrs)

An unexpected outcome of this research was that there were remarkably few gender differences arising from the data. Women and men, at least in terms of their attitudes to youthful and mature identities, appeared to have very similar patterns of responding to the issues raised. These patterns included a reduced concern about the opinion of others and a sense of being at ease with their current age, buoyed up by a perception that they looked younger than they thought they would and an emphasis on the importance of maintaining a youthful identity adapted, by degrees, to mature circumstances.

\section{Attitudes to Other Generations}

The use of generational identity emerges as a complex set of markers of distinctiveness, with identification between generations depending upon the type of association being described. There was some evidence that, as suggested by Featherstone and Hepworth (1989), a blurring of ageidentities was taking place, at least with respect to younger generations, 
but also indications that boomers saw themselves as a distinctive generational group with particular maturational demands. Social attitudes were seen as the main marker of similarity between boomer and succeeding generations and of distinction from preceding ones. The most salient marker of generational attitudes to the older generation was one of difference, based on historical circumstances, social attitudes and expectations:

I think outlook and attitude is very different now. My generation and the up and coming generation are more accepting of people and the way that people live and there's no stigma now. (Female: 52 yrs)

I find, I mean, my parents, I'm in a generation way further apart from them than my children are from me. (Male: 54 yrs)

I think my generation were a lot younger than my dad's generation at the same age. (Male: $58 \mathrm{yrs}$ )

The evidence, then, suggests that boomers tend to see themselves as different from the preceding generation. This was almost exclusively conceived in terms of their parental generation as a family generation, rather than in terms of popular cultural markers. But there were also continuities, for example in terms of attitudes to spending and credit, which were also put down to early personal experience:

I remember my parents not wanting to get into debt. (Female: 55 yrs)

I'm a bit careful with what I spend... and I don't like to waste anything, but, I think it's the way we were brought up. (Female: 53 yrs)

Occasionally this was seen as a distinctive marker between themselves and younger age groups, and sometimes as a continuum reflecting availability and affluence following the austere lives of their parents:

I think my parents didn't have half the life that I had, they just, I think they sacrificed everything for their kids whereas these days anything I want I'll go and buy. (Male: $60 \mathrm{yrs)}$ 
Generally speaking the boomers in our study identified similarities between themselves and younger generational groups, both in terms of their own children and more widely as an age group, indicating, perhaps, a cultural shift as well as a perceived change in attitudes within families. This was particularly evident in areas of style, taste and social attitudes:

Oh I think I'm closer to my kid's generation. (Male: 52 yrs)

Well, generally speaking... the younger generation... they're much more throw-away, but then I think sometimes a lot of the values are the same as ours... they're more tolerant....I'm more tolerant than I would have been years ago. (Female: $57 \mathrm{yrs}$ )

Boomers characteristically saw the 'blurring' of generations as something that had taken place between themselves and these younger groups:

I've got daughters in their thirties. I have to say and I think they'd probably agree with this, the way we think about life is very similar. (Female: $55 \mathrm{yrs}$ )

To put it bluntly I see no difference. You see the plethora of people under sixty and around thirty as being in my cohort. I see everybody in that age band as clever as me, as well paid as me or as prejudiced about new technology or not as I am. (Male: $59 \mathrm{yrs}$ ).

Rather than simply reflecting a desire to 'stay young', attitudes to middle and later life interact with generational identification to produce a middle way for a more mature imagination. The way that respondents cope with these multiple influences is reflected in an attempt to balance them in ways typically expressed by the following examples:

Our generation, you've got a little bit of the past and a little bit of the future. (Male: $55 \mathrm{yrs}$ )

I don't see myself as old, but neither do I see myself in a way as being young, or in my, as if I was still in my thirties. Because I think I've learned a lot since then. But I like to think I have something in common with people in their thirties which I feel I do have. (Female: $52 \mathrm{yrs}$ ) 
The more, you know, experience you've got, the longer you've lived and maturity and whatever and you look at things that are going on in the world, your attitude kind of modifies. (Male: 57 yrs)

Occasionally, perceived affinities with preceding generations also evidenced a maturational component, for example:

The older you get, the more you appreciate the values of the previous generation. (Female: 55 yrs)

The hesitancy of some of these quotes, perhaps reflects the novelty, both personally and culturally of this phenomenon. Maturity, then, as a personal discontinuity with younger parts of the life-course, which is also linked to one's current life circumstance and accrued experience. This coexists with a desire to maintain a youthful lifestyle and preserve certain forms of familial continuity.

Finally, in this section, a striking aspect of the qualitative interviews, as the quote below indicates, was that while respondents often had not explicitly considered their attitudes to ageing, the majority appeared to have little difficulty articulating a coherent viewpoint when asked. This in itself evidences a capacity for mature reflection on both ageing and life course processes:

I think we accept that we've got to grow older, but I think we want to put off that old age for as long as we can. I don't think that we necessarily feel the age we are. We might look it - especially to younger people, but I think inside we don't feel that much different. I think growing up in the time that we did has contributed to that. (Female: 55 yrs).

\section{Strategising Ageing through Consumption Patterns}

How, then, are these attitudes to ageing, a tendency to feel youthful tempered by a mature imagination, plus a desire to be close to younger rather than older generations, reflected in particular consumption practices? Boomers appear to hold particular views about the process of personal ageing, the importance of other's perceptions and the similarities and differences between generations. It is important to see whether pat- 
terns of consumption are used to support the positions taken and how they develop strategies to enhance their identities in desired directions.

\section{Strategies for Appearance and Clothing}

When our 150 respondents were asked how important it was to maintain appearance, $83 \%(n=125)$ said it was important or very important. In terms of consumption, this appears to be a pattern that was learned as part of teenage experience, subsequently modified to fit norms associated with mid to later life. Dress codes, and a certain degree of 'following trends' when they were younger (e.g. wearing flares/mini-skirts in the $60 \mathrm{~s})$, had been a feature of teenage consumption for boomers. Several of the respondents reported that the way they dressed was a means through which they could express changing attitudes at that time:

You still wanted to try and keep up with the fashion and the music and there was still a sense of excitement that we were part of a world that was changing...I suppose I was a bit of a rebel. I was the one that went to school not in the school uniform...the school uniform was royal blue and I went in pale green, in white tights with white lipstick which was not allowed...I suppose that was my way of saying "I'm going to be different". (Female: $52 \mathrm{yrs}$ )

By the time boomers have reached midlife, the consumption of clothing is more closely associated with the erasure of differences based on age:

I think its becoming more difficult (to distinguish between the generations) to be quite honest.... Yes its definitely the way that they present themselves, the things they're wearing now, people in their 50 's and $60^{\prime}$ s are wearing things that you think, well, people in their $30^{\prime}$ s and 40 's are wearing the same thing, but they look fine, its not a problem.... So there's a bridge between generations where they still look OK and I think when I was growing up, old ladies dressed like old ladies didn't they and you don't see that so much now. (Female: 52 yrs)

Rather than being simply a change in what is considered fashionable, however, the apparent difficulty that this respondent has in distinguishing age by dress code may be the accumulation of a series of individual choices to minimize age as a social category. As boomers reach mid and later life, a reported lack of concern with adult ageing is tempered by a 
clear sense of 'appropriateness' of dress and behaviour, with strong agerelated associations:

You don't do anything stupid in your mid fifties. (Male: 56 yrs)

Yes, people expect you should behave in a certain way when you're 57. And I think there's a very fine line to tread....I mean I would hate to be mutton dressed as lamb. (Female: $57 \mathrm{yrs)}$

Strategies that incorporated dress codes that were considered ageappropriate and age-neutral were an important means by which generational relations and associations influence the presentation of self. The way in which those with a continued interest in fashion accounted for their consumption practices suggests that one of the main underlying factors was the desire to wear clothing that 'suited'. For example, many women reported that they liked to follow the trends, but that they were conscious of the fact that 'young' clothes did not always suit them. They reported a sense of being 'realistic' in what they can and cannot wear, and reported avoiding items they consider to be too young for them, or clothes that were not suited to their figure:

I wouldn't wear my daughter's clothes because I might look ridiculous. (Female: 52 yrs)

The desire to wear clothes that 'suited their age' worked in both directions. Two women, for example, reported that they were not at the "twin set and pearl" stage they associated with the older generation, and there was a real sense of hope that they'd got it 'right'. One man remarked that for him, getting it 'right' involves achieving a balance between buying clothes that do not make him look old, but that are still appropriate for a man of his age. These were seen as an important element in maintaining positive intergenerational relations.

Hopefully you buy...stuff that is nice and appropriate and flattering, but is appropriate for the age group, but wouldn't be such that your daughter wouldn't be seen dead...they're quite happy to be with you wearing those sort of things, they don't feel as if you're an old fuddy duddy who they associate it with. (Male: $55 \mathrm{yrs)}$ 
Many of the respondents recognised that certain shops were aimed at different generations, and again, their use (or avoidance) of such shops similarly worked in both directions, as the following quote suggests:

If I wanted to go and buy some new clothes, there are shops I wouldn't think of going into, I wouldn't even walk in, because I know I would say, "That's not for me". If I was 20 years younger I might go there. Then there are shops that I would not go into but my parents would have bought in. Those sort of shops are disappearing in a way. (Male: $55 \mathrm{yrs}$ )

Respondents recognised that some shops were more suited to 'younger generations', and many reported that they would not even go into these shops. However, some of the female respondents reported liking and buying clothes in similar shops to their daughters. They also reported sharing clothes with their daughters in a way that they had not done with their mothers:

I think of my mother at my age, I think that she was old and I would never borrow her clothes for instance.... and yet, my daughter would borrow my clothes. (Female: $57 \mathrm{yrs}$ )

My daughter will wear my clothes and I don't often wear hers, but we like similar things and there's not that distinct difference in where I would shop and where she would shop. There is some difference, but it's not as marked as it would have been with my mother where she hated going into some of the shops I wanted to go into. (Female: $51 \mathrm{yrs}$ )

Whether or not particular boomers consider common or different dress codes to be shared between themselves and their children probably depends on the age and fashion sense of the child in question. The main point here is that what at first glance appears to be purely personal consumption decisions about style and taste, are, on closer inspection, heavily influenced by considerations of generational association. Strategies that neutralise associations with older 'fuddy-duddy' generational themes and enhance smooth relations with younger generational groups, are at a premium. Consumption decisions about dress, used in the boomer teenage years to express individuality or rebelliousness, may also 
be deployed on the very different ground of midlife to mark the rejection of traditional age-expectations.

The importance of clothing as a generational strategy, a youthful practice, modified to reflect mature consumption patterns, indicates one way in which boomers manage an ageing identity in midlife. This consists primarily of a toning down of age signifiers, a preference for simplicity and elegance, which if not exactly ageless aspires to being ageneutral. Key to the successful management of identity appears to be an understanding of 'appropriateness'. Appropriateness, in this generationally charged context involves, then, a de-emphasising of age signification plus sensitivity to tacit boundaries that if crossed are subject to internalised and potentially external sanction. Clothing as a principal site of consumer activity is used as a prop to stay within age-appropriate boundaries for appearance that if not explicitly enforced, are tacitly understood. This form of masquerade both displays and disguises age through the maintenance of 'appropriate' consumption decisions.

\section{Strategies for bodily maintenance}

When asked about patterns of consumption that could be interpreted as maintaining bodily functioning and appearance, only $27 \%(n=38)$ reported exercising less than once per week; $40 \%(n=59)$ used vitamins or minerals to supplement their diet. In general, baby boomers felt as if they are a generation that is conscious of being active and who will take up new consumption pursuits, particularly as they concern fitness and health:

I think we're a lot more active generation. I think we expect more out of life and I think we're willing to take on more. I don't think we're willing to settle into thinking I'm too old to do that now. I think our generation is more likely to give something a go, have a go at it...for instance, this year I've started having tennis lessons and for somebody who used to avoid PE at all costs at school, so at 53 you start saying "Oh I think I'll start playing tennis now". (Female: 53 yrs)

Boomers felt that health-related issues are increasingly emphasised in wider society, with magazines, booklets and adverts aimed at raising 
awareness about diet, exercise and health checks. Many report taking such advice:

I think that as we've got older and you get older, the newspaper articles about what you are what you eat and you have to exercise and things like that, more so I think than any other generation that has gone before us, we're kind of taking all this in all the time aren't we? You get your blood pressure checked and you get your cholesterol checked and we are more sort of body conscious, more into I suppose trying to prolong our lives, but being healthier while we do it. We don't want to... I don't see the sense in living for a long, long time, if you're ill all of that time. (Female: $52 \mathrm{yrs}$ )

Respondents mainly talked about their awareness of health in relation to preventative measures (in the form of routine checks at doctors, dentists). If they thought there was problem, they report visiting a professional quickly, whether a pharmacist, dentist or doctor, in order to check their concerns. Healthy diet appeared as one of the main ways in which respondents reported maintaining their health. They report that as they get older, they are increasingly aware of what a healthy diet consists of, and the positive effects of eating well:

I think in society generally we have become aware of needing to look after ourselves much more in terms of diet and exercise... I certainly think we are thinking quite carefully about diet. (Male: 55 yrs)

It was very common for the respondents to say that they used to exercise a lot, had a long period when they did not exercise, and then as they got older, they took it up once more. On the whole, the ideal was to stay healthy and active for as long as possible and certain consumption habits were seen to be important means of maintaining existing good health:

I go to the gym, I swim, I try and keep fit and healthy. Because I think yeah your body deteriorates and as you get older you lose bone density and things like that. So the more you can do in advance and preparation I suppose for getting older. Keep more flexible, supple, yeah has got to be better for you. So long as you don't overdo it, I mean I think some people can get very fanatical about exercise. (Female: $53 \mathrm{yrs}$ ) 
Occasionally these 'maintenance' narratives are supplemented by deeper, more existential concerns:

It's all to do with, I suppose, the fear of dying I suppose, if that's, that's what it is with me. It's not, it's nice to be fit and healthy and be able to walk up the road and not, not being out of breath and all that kind of thing. But now I've got a bit of high blood pressure but it's to do with the fear of dying it really is about what the children are going to do. (Male: $52 \mathrm{yrs}$ )

This man's own father had died at the age of 51, which left him with a heightened sense of mortality. However, reference to family history does not necessarily result in healthy consumption. One man was relatively unconcerned about his drinking habits and diet because his mother had lived until she was 93 yrs old even though she drank a lot of alcohol. The sentiment is clear - 'she got away with it, and so will I'. His parents were not particularly health conscious and lived to an old age, so why should he worry when he could: 'just enjoy life really, that's the bottom of it'. (Male: 51yrs).

While lessons can be learned from the health patterns of preceding generations, a core motivation behind strategies for exercise and diet reflect social choices being made about retirement plans. For boomers in long-term relationships, both maintenance in the here and now and future plans reflect shared decisions and the notion that retirement and midlife is a time for companionship and leisure relationships, expressed as 'things done together' and a joint attitude to staying healthy, the better to enjoy retirement and later life. It is an active and conscious commitment to these ideas, and an extensive array of consumer products and services such as gyms, classes, vitamins and healthy food that mark this out as a key generational activity, at least in comparison to older cohorts.

For a number of respondents, the choice to consume certain sporting activities was clearly taken to enhance generational bonds with adult children, for example:

I love tennis, I'm not particularly good at it yet....it's a sport you can play at any age... my son is very much into tennis so its an interest I can share with him which has spurred me on to really have lessons because then I can go on the tennis courts and have a game with him. Its something else we can share. (Male: $61 \mathrm{yrs)}$ 
So while the consumption of sport and healthy foods may be most commonly associated with the personal, or partnership tasks of maintaining the ageing body and the prudent avoidance old age, the choice of activity can also provide a source of common bonds between generational groups.

\section{On being a boomer}

\section{Balancing Mature and Youthful Identities}

The extent to which boomers define themselves as a distinctive group of consumers emerges as having as much to do with their attitudes to youthfulness, maturity and to other generations as it does the function of the product at hand. There are common themes which may have their origins in the attitudes of the 'sixties generation' adapted to mature lifestyles. Personal ageing is, for example, seen as something that, culturally speaking, requires managing if it is to be successfully avoided but is not seen as overly problematic. Taken together, these findings indicate a complex relationship between youthful and mature selves. Maturity is evidenced in terms of comfort with current age and looking forward in terms of time left; youth in terms of feeling more youthful than their actual age implied and a blurring of differences with younger generations. It appears that baby boomers share certain characteristics and think about personal ageing and generational characteristics in ways they perceive to be different to traditional patterns, and that these are expressed in particular consumption choices. The ageing boomer, then, draws on a series of mature strategies to balance cultural and life-stage issues and while boomers deny concerns about ageing and age-differences with younger groups, they do it in a particularly 'boomerish' way.

'Staying young' was maintained in the here and now by associating with younger generations, an expressed lack of concern with one's own age, and enthusiasm for a cultural blurring between generational groups. Work, however, was a particular area in which age-discrimination had been experienced and where maintaining a balance between youthful and mature identities became viewed as problematic. 
The strategies adopted were neither exclusively 'youthful' (Featherstone \& Hepworth 1989), nor 'mature' (Biggs 1999). Rather, boomers attempt to find a balance between the two, which serves to sustain youthful lifestyles adapted to the requirements of a mature identity.

\section{Strategies for Intergenerational Connection}

A clear theme emerging from our research is a 'boomerish' desire to erase differences with younger generations, thereby reducing negative associations arising from boomer's own experience of their own parents. This extends to a rejection of associations with old age in general and ambivalence toward adult ageing and late life experience. Here, the manipulation of age and appearance is a powerful guiding principle for consumption activity during the middle years, indicating that the active strategising of consumer choices is not purely the domain of the young. While boomers may have learned some of these practices during earlier parts of the life course, they adapt them to their current situation, an influence of process rather than content. It is in this context that tacit norms of 'appropriateness' come into their own. These appear sotto voce as indicators of what it means to be a successful midlife boomer and while boomers appear to experience a relaxation of the power of other people's opinions, they are careful not to cross a tacit boundary of how age-neutrality in later midlife should be presented, especially in the presence of younger people. Successfully managing this boundary, through the deployment of consumption choices, is the badge of a successful mature identity.

The strategising of age-related consumption among this group does not appear to be an exclusively protective masquerade that some authors (Woodward 1991; Biggs 1997) have envisaged in late life, where it serves to protect an embattled 'inner self' from the slights of ageism. In addition to the protective function, strategies for identity management can also have a connective role (Biggs 1999), whereby appearances are managed in the service of an outward-going link to younger generational groups. These boomers do not perceive themselves to be 'old' in attitude or overly concerned with the age they feel themselves to be. They are generally comfortable with their age and want to keep things that way and consumption is not so much used to deny age, as to enhance the maintenance of existing age-neutral identities. Connection here is directed pri- 
marily at appearances and activities that bring boomers closer to younger generations, centred on an attempt to erode specific age differences while recognising the advantages of maturity in the here and now.

\section{Strategies for Intergenerational 'Downward Blurring'}

The tendency toward strategies of connection noted above is not then marked by a general erosion of difference between generations, as suggested by Featherstone \& Hepworth (1989). Rather, 'blurring' as perceived by boomers in the United Kingdom is unidirectional, referring only to themselves and the succeeding generation. A cultural tendency to valorise youth has been modified, through consumption, to a strategy of 'downward blurring' that emphasises intergenerational solidarity with succeeding adult generational groups. It became the subject of deliberate interpersonal strategies to foster and maintain younger friendships within and outside the family.

This tendency toward 'downward blurring' raises some interesting questions for contemporary theories of intergenerational relations. A focus on a single, downward generational bond, to the exclusion of continuities with preceding generations would mean that boomers lose an important source of resistance toward the pressures of cultural conformity - namely the oral history and practical wisdom transmitted from older to younger generations (Attias-Donfut 2003; Attias-Donfut \& Wolff 2005) and also the degree of solidarity expressed between generations (Bengtson, Elder \& Putney 2005). As such their strategies might severely underestimate the connective role played by intergenerational bonds of kinship: upwards as well as downwards. The UK Boomer cohort would appear to mark a significant difference in these intergenerational strategies if they are seeking continuity through the younger generation alone. A rift with older generational groups may result in a loss of oral memories and resistance to dominant cultural patterns of consumption that lead to an avoidance or denial of the ageing process. The implications of downward blurring are by no means clear. A blurring of generational differences may prove to have mixed blessings for intergenerational solidarity, with increased similarity, but possibly increased conflict if different generational groups are driven to compete on the same ground. 
In the USA, Stewart and Torges (2006) characterise the American boomers as being: 'Narcissists who became individuals with well developed collective identities' (2006: 34). These collective identities, however do not, in the UK context, appear to reflect a peer-cohort approach as identified by Antonucci, Akiyama \& Merline (2001) and there was little evidence of a same-age culture based on common historical experiences. Rather, UK boomers rely on identification with the succeeding generation to protect themselves from the narcissistic slights of ageing bodies and passing of generational dominance, with consequences that have yet to fully work themselves out.

\section{Conclusion: Consumption, Ageing and Cohort}

Consumption that is used to influence appearance, through clothing and bodily maintenance to diet and exercise, emerges in this study as part of a wider strategy to manipulate age-identity and relations with younger generations. The preferred strategy was to use consumption practices as props to a mature identity, one that balanced a desire to remain 'youthful' in outlook, but 'mature' in attitude. While social ageism was rarely mentioned, other than in certain cautionary narratives about work, it was the clear and widely acknowledged intention to develop appropriate links with the immediate succeeding generation. This desire, however, was not extended upward to preceding generations, who while they may share similar characteristics in intimate and family relations, were not a source of identification, or guides to consumption practices.

In their attitudes to personal ageing, boomers thought of themselves as not concerned with age, feeling more comfortable with their age than they had in previous parts of the life course. They felt younger than their actual age and thought in terms of 'time left' as well as time since childhood. They tended to draw upon both past experience and future expectations in evaluating their life experience.

In their attitudes to younger and older generational groups, boomers tended not to identify with their parents' generation, excepting in very specific areas, often using characteristics associated with older generations in contrast to themselves. They saw few differences between themselves and younger age groups, believing that in this context generational 
differences were becoming less marked. Older, parental generations are used as a point of contrast, as the subjective location of a cultural rift around consumption choices, social attitudes and tastes. A dominant strategic aim would be to develop social relationships with younger generations and to maintain ones current body and health in the face of increasing signs of ageing.

While support for the idea that boomers may be a self-aware group appears limited, there are common attitudes and strategies for addressing adult ageing, which indicate that boomers may think in similar ways about these issues. The accumulation of these individual choices, do appear to evidence a significant shift in cultural attitudes to mid and later life. And while it is difficult to say whether baby boomers are the active protagonists of this process or simply caught up in a wider historical phenomenon, they do desire new forms of ageing and of growing old.

\section{Acknowledgements}

The research discussed in this paper was supported by a grant from the Economic and Social Research Council/ Arts and Humanities Research Council Cultures of Consumption Research Programme (Grant no. RES154-25-0003). The authors are grateful to the Research Councils for their financial support.

\section{References}

Antonucci, T. C., Akiyama, H., \& Merline, A. (2001). Dynamics of social relationships in midlife. In M. E. Lachman (ed.), Handbook of Midlife Development. (pp. 571-598). Chichester: Wiley.

Attias-Donfut, C. (2003). Family transfers and cultural transmissions between three generations in France. In V. L. Bengtson \& A. Lowenstein (eds.), Global Aging and Challenges to Families. (pp. 214-252). New York: Aldine de Gruyter.

Attias-Donfut, C., \& Wolff, F-C. (2005). Generational memory and family relationships. In M. L. Johnson (ed.) in Association with Bengtson, V. L, Coleman, P and Kirkwood, T., The Cambridge Handbook of Age and Ageing. (pp. 443-454). Cambridge: Cambridge University Press. 
Bengtson, V. L., Elder, G. H., \& Putney, N. M. (2005). The life course perspective on ageing: Linked lives, timing, and history. In M. L. Johnson (ed.) in Association with Bengtson, V. L, Coleman, P and Kirkwood, T., The Cambridge Handbook of Age and Ageing. (pp. 493-501). Cambridge: Cambridge University Press.

Bernard, M., Bartlam, B., Biggs, S. \& Sim, J. (2004). New lifestyles in Old Age: health identity and well-being in Berryhill Retirement Village. Bristol: Policy Press.

Biggs, S. (1997). Choosing not to be old? masks, bodies and identity management in later life. Ageing $\mathcal{E}$ Society, 17(5): 553-570.

Biggs, S. (1999). The Mature Imagination. Buckingham: Open University Press.

Biggs, S. (2005). Beyond appearances: Perspectives on identity in later life and some implications for method. Journal of Gerontology: Social Sciences, 69B: S118-S127.

Edmunds, J. \& Turner, B. (2002). Generations, Culture and Society. Buckingham: Open University Press.

Featherstone, M., \& Hepworth, M. (1989). Ageing and old age: reflections on the post-modern life course. In B. Bytheway (ed.), Becoming and Being Old: Sociological Approaches to Later Life (pp. 143-157). London: Sage.

Gilleard, C., \& Higgs, P. (2002). The third age; class cohort or generation? Ageing $\mathcal{E}$ Society, 22(3): 369-382.

Gilleard, C., \& Higgs, P. (2005). Contexts of Ageing: Class Cohort and Community. Cambridge: Polity Press.

Grenier, A. (2007, in press). Crossing age and generational boundaries Journal of Social Issues 63(4): 713-727.

Harkin J. \& Huber, J. (2004). Eternal Youths: How the Baby Boomers are Having their Time Again. London: Demos.

Huber, J. \& Skidmore, P. (2003). The New Old: Why Baby Boomers won't be Pensioned Off. London: Demos.

Kaufman, G., \& Elder, G. (2002). Revisiting age identity. Journal of Aging Studies, 16(2): 169-176.

Kynaston, D. (2007). Austerity Britain 1945-51. London: Bloomsbury.

Mannheim, K. (1952). The problem of generations. In K. Mannheim (ed.), Essays on the Sociology of Knowledge. (pp. 276-322). London: Routledge. 
Metz, D. \& Underwood, M. (2005). Older, Richer, Fitter, London: Age Concern, England.

Sandbook, D. (2005). Never Had it so Hood: A History of Britain from Suez to the Beatles, London: Brown.

Stewart, A. J. \& Torges, C. M. (2006). Social, Historical, and Developmental Influences on the Psychology of the Baby Boom at Midlife. In S. K. Whitbourne \& S. K. Willis, S. L. The Baby Boomers Grow Up: Contemporary Perspectives on Midlife. (pp. 22-41). New York: Lawrence Erlbaum Associates.

Woodward, K. (1991). Aging and Its Discontents: Freud and Other Fictions. Bloomington and Indianapolis: Indiana University Press. 